\title{
Hirayama disease: Role of diffusion tensor imaging
}

\author{
Dinesh Sharma, Shruti Thakur, Chidanand Chavan, Anupam Jhobta
}

\section{CASE REPORT}

A 28-year-old male patient presented with progressive weakness of both forearms and hands along with clawing of hands for past eight years. Right side was affected more than the left. There was no history of similar illness in the family. There was no past history of any prolonged illness in childhood. There was no history of sensory, pyramidal or bladder dysfunction. There was atrophy of muscles of both forearms and hands. Muscle power was normal in both upper limbs. Nerve conduction studies showed reduced amplitude in bilateral median and ulnar nerves. Tendon reflexes were normal. Magnetic resonance imaging (MRI) examination was performed in non-flexion and flexed position. Subsequently, diffusion tensor imaging (DTI) was performed in non-flexion, which very clearly showed the cord atrophy at $\mathrm{C}_{7}-\mathrm{T} 1$ level (Figure 1). This cord atrophy was not appreciated on MRI flexion and non-flexion studies. The diagnosis of Hirayama disease (HD) was thus established on DTI.

Dinesh Sharma ${ }^{1}$, Shruti Thakur ${ }^{2}$, Chidanand Chavan ${ }^{3}$, Anupam Jhobta 4

Affiliations: ${ }^{1} \mathrm{MD}$, (Radiodiagnosis), Assistant Professor, Department of Radiodiagnosis and Imaging, Indira Gandhi Medical College Shimla, India; ${ }^{2} \mathrm{MD}$, (Radiodiagnosis), Senior Resident, Department of Radiodiagnosis and Imaging, Indira Gandhi Medical College Shimla, India; ${ }^{3} \mathrm{MD}$, Student (Radiodiagnosis), Junior Resident, Department of Radiodiagnosis and Imaging, Indira Gandhi Medical College Shimla, India; ${ }^{4} \mathrm{MD}$, (Radiodiagnosis), Associate Professor, Department of Radiodiagnosis and Imaging, Indira Gandhi Medical College Shimla, India.

Corresponding Author: Dinesh Sharma, Assistant Professor, Department of Radio diagnosis and Imaging, Indira Gandhi Medical College Shimla, India 171001; Ph: +919418499909; Fax: +911772658339; Email: dineshss108@gmail.com

Received: 30 October 2012

Accepted: 17 November 2012

Published: 01 March 2013

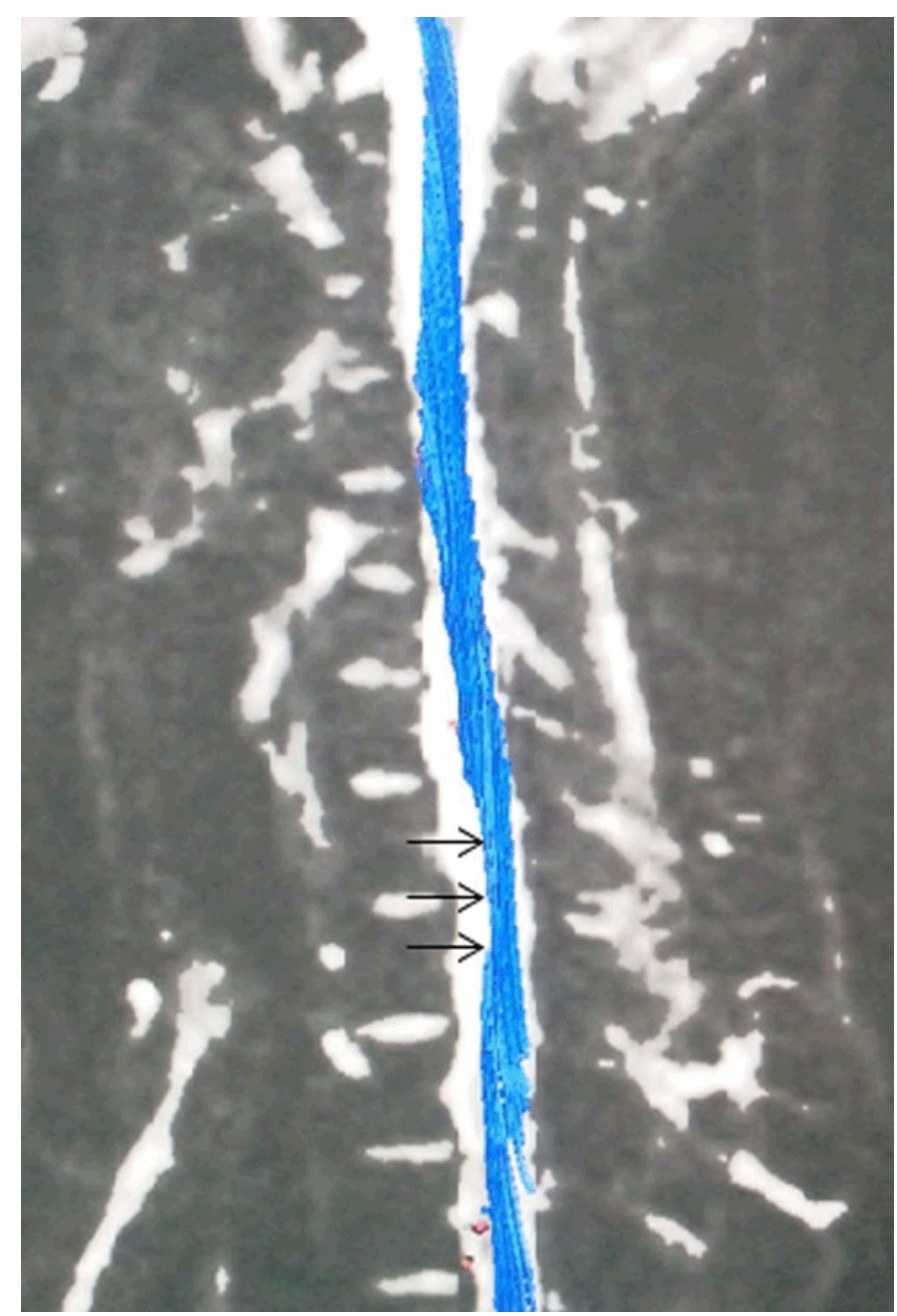

Figure 1: Diffusion tensor magnetic resonance image acquired in non-flexion shows atrophy of spinal cord at $\mathrm{C}_{7-\mathrm{T}} 1$ level (arrows).

\section{DISCUSSION}

Hirayama disease (HD) is a non-progressive, juvenile, spinal muscular atrophy of distal upper limbs and is a kind of cervical myelopathy related to flexion movements of the neck. Imbalance in growth of 
vertebrae and dura mater causes a loss of normal dural slack in extension. As a result of this, the tight dural canal causes compression of the spinal cord [1]. It is suggested that HD might be due to microvascular changes following chronic trauma to spinal cord during flexion and extension of the neck [2]. On non-flexion MRI studies, asymmetric cord atrophy especially at the lower cervical level is highly suggestive of HD [3]. Furthermore, the magnetization and diffusion MRI histograms of the cervical cord suggest that the cord damage in HD extends beyond that seen on routine MRI scans [4]. In our opinion, this atrophy of the spinal cord is best demonstrated on diffusion tensor imaging. This makes diffusion tensor imaging a valuable tool in diagnosing Hirayama disease without subjecting the patient to a flexion study of the cervical spine.

\section{CONCLUSION}

Diffusion tensor imaging is simple, fast and accurate method for diagnosing Hirayama diasease without subjecting the patient to flexion magnetic resonance imaging study.

$* * * * * * * * *$

Sharma D, Thakur S, Chavan C, Jhobta A. Hirayama disease: Role of diffusion tensor imaging. International Journal of Case Reports and Images 2013;4(3):184-186.

$* * * * * * * * *$

doi:10.5348/ijcri-2013-03-290-CI-11

$* * * * * * * * *$

\section{Acknowledgements}

Dr Ashwani Tomar, Dr Vijay Thakur, Dr R.G. Sood, Department of Radio diagnosis and Imaging, Indira Gandhi Medical College Shimla, India -171001.

\section{Author Contributions}

Dinesh Sharma - Acquisition of data, Analysis and interpretation of data, Drafting the article, Critical revision of the article, Final approval of the version to be published

Shruti Thakur - Acquisition of data, Analysis and interpretation of data, Critical revision of the article, Final approval of the version to be published

Chidanand Chavan - Acquisition of data, Drafting the article, Final approval of the version to be published

Anupam Jhobta - Analysis and interpretation of data, Critical revision of the article, Final approval of the version to be published

\section{Guarantor}

The corresponding author is the guarantor of submission.

\section{Conflict of Interest}

Authors declare no conflict of interest.

\section{Copyright}

(C) Dinesh Sharma et al. 2013; This article is distributed under the terms of Creative Commons Attribution 3.0 License which permits unrestricted use, distribution and reproduction in any means provided the original authors and original publisher are properly credited. (Please see www.ijcasereportsandimages.com/copyright-policy.php for more information.)

\section{REFERENCES}

1. Hirayama K. Non - progressive juvenile spinal muscular atrophy of the distal upper limb (Hirayama's disease). In: De Jong JMBV, ed. Handbook of Clinical Neurology. Amsterdam, the Netherlands : Elsevier;1999;15:107-20.

2. Hirayama K, Tomonaga M, Kitano K, Yamada T, Kojima S, Arai K. Focal cervical poliopathy causing juvenile muscular atrophy of distal upper extremity: a pathological study. J Neurol Neurosurg Psychiatry 1987; 50:285-90.

3. Chen CJ, Chen CM, Wu CL, Ro LS, Chen ST, Lee TH. Hirayama Disease: MR Diagnosis. AJNR Am J Neuroradiol 1998; 19:365-8.

4. Gallo A, Rocca MA, Tortorella P, Ammendola A, Tedeschi G, Fillipi M. A multiparametric brain and cord MR imaging study of a patient with Hirayama Disease. AJNR Am J Neuroradiol 2006;27:2115-17. 
Access full text article on other devices

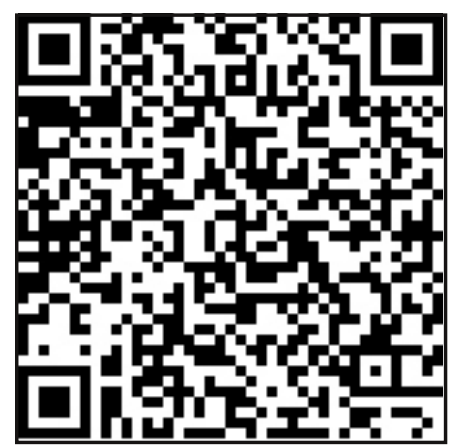

Access PDF of article on other devices

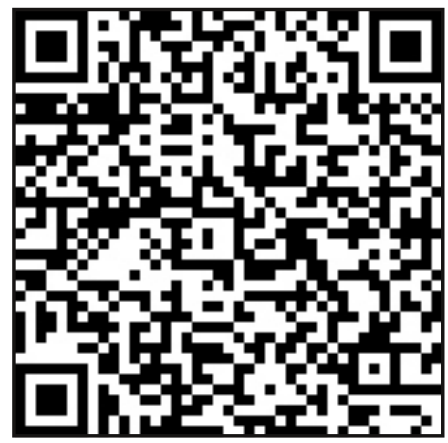

